\title{
A New Phenol Glycoside from Root Exudates of Peperomia pellucida L. HBK. and its Role in Plant Invasion
}

\author{
Suparna Mandal Biswas ${ }^{1 *}$, Nabanita Chakraborty', Soma Rani Patra ${ }^{2}$ \\ and Prasanta C. Bhowmik ${ }^{3}$
}

\begin{abstract}
Peperomia pellucida is an annual, shallow-rooted, succulent, delicate, glabrous herb. It is a native weed species of tropical North and South America, and it is now pantropic in distribution and abundant in India as an invasive aggressive colonizer. Medicinal properties of the plant have been well documented but no work has been done to find out the reason behind its invasive aggressive nature. The objective of our present work was to study the allelopathic activity of allelochemicals released by root exudates of $P$. pellucida which may play an important role in invasive and aggressive properties of the plant. Root exudates of $P$. pellucida were collected in root exudates trapping system. Main compound was isolated from methanol fraction of root exudates of $P$. pellucida, purified by thin layer and column chromatography and finally subjected to mass spectra, infrared, and nuclear magnetic resonance (both ${ }^{1} \mathrm{H}$ and ${ }^{13} \mathrm{C}$ ) for complete structural elucidation. In vitro allelopathic activities of the compound were studied by rice, wheat and mustard seed bioassays. A new phenol glycocide [(6-(4hydroxyphenoxy)-tetrahydro- $2 \mathrm{H}$-pyran-2, 3, 4, 5-tetraol); $\mathrm{C}_{11} \mathrm{H}_{14} \mathrm{O}_{7}$; Mol. Wt. 258] has been isolated and purified from root exudates of $P$. pellucida. This pure compound exhibited significant allelopathic activities on rice, wheat and mustard seeds in vitro bioassay experiment. This compound showed maximum inhibitory activity on rice, than in wheat and mustard bioassays. Peperomia pellucida released a phenol glycoside through root exudates into rhizophere which may act as a major allelopathic agent and may be responsible for its invasive and aggressive nature.
\end{abstract}

Keywords: Phenol glycoside, Peperomia pellucida L. HBK., root exudates, invasive, allelopathic effect.

\footnotetext{
${ }^{1}$ Agricultural and Ecological Research Unit, Indian Statistical Institute, 203, B. T. Road, Calcutta 700108, India

${ }^{2}$ Department of Biotechnology, Gitam Institute of Science, Gitam University,Visakhapatnam 530045

${ }^{3}$ Stockbridge School of Agriculture, University of Massachusetts, 18 Stockbridge Hall, Box 37245, 80 Campus Centre Way, Amherst MA 01003-7245, USA
}

\footnotetext{
* Corresponding Author. Address: Agricultural and Ecological Research Unit, Indian Statistical Institute, 203, B.T. Road, Kolkata 700108, INDIA. Tel: (+91) (033) 25753225, Fax: (+91) (033) 25753049. E-mail: suparna@isical.ac.in DOI: 10.32945/atr3922.2017
} 
Biswas et al

\section{INTRODUCTION}

Peperomia pellucida L. HBK. (Piperaceae) is an annual, succulent, delicate, and glabrous herb with weak erect stems. The plant flourishes in moist as well as in shady areas and can grow to a height of 15 to $45 \mathrm{~cm}$. It is characterized by succulent stems, shiny, heart-shaped, fleshy leaves and tiny, dot-like seeds attached to several fruiting spikes (Mosango 2008). The English name of the plant is shiny bush. It is found mainly in South American and Asian countries. It is widely distributed in the tropical and subtropical regions and is occasionally cultivated and naturalized as weed (Arrigoni-Blank et al 2002, Ghani 1998).

It is an edible plant and is frequently used as a leafy vegetable or condiment in many parts of the tropics. Egwuche et al (2011) reported that the proximate and mineral composition of $P$. pellucida leaf is very high. Nutritional composition and phytochemical properties are reported to vary with agroclimatic conditions, humidity and species of the plant (Iqbal \& Bhanger 2006). Previous phytochemical analyses on this plant revealed the presence of flavonoids, lignans, xanthone glycoside, peperomins, etc., with strong antimicrobial activity (Khan \& Omoloso 2002 , Xu et al 2006). Several studies have substantiated the antimicrobial, antiinflammatory, analgesic, antifungal, and antihyperuricemic activities of the plant (Ragasa et al 1998, Bojo et al 1994, Sio et al 2001, Antioniolli et al 2003).

These findings were mainly focused on the medicinal properties of crude extracts of $P$. pellucida L. but no work has been done on the invasive success and wide distribution of the plant. Ens et al (2009) found that volatile compounds released by roots of an invasive plant, bitou bush (Chrysanthemoides monilifera spp. rotundata) inhibit the growth of native seedlings. Khosla et al (1980) found that Parthenium hysterophorus is a noxious invasive weed that secretes a substance through root exudates-namely parthenin- which is dangerously toxic. Our present study mainly focused on the invasive success of $P$. pellucida that may be related to its allelopathic effects on the surrounding rhizophere species. In natural habitat, the herbaceous plants emitted chemical signals through root exudates and invasive and allelopathic nature of the plants are mediated mainly by this chemical. The roots of $P$. pellucida are fibrous in nature and released chemical signals mainly through root exudates. Our present study was designed to identify chemicals present in root exudates of $P$. pellucida and to assess the bioactivity of the compound via plant bioassay.

\section{MATERIALS AND METHODS}

\section{Collection of Root exudates from P. pellucida}

Root exudates (RE) were collected after putting the plants into the root exudates collecting glass apparatus specially designed for plants with fibrous root, eg $P$. pellucida. A self-designed horizontal tube like glass ware with stopper and funnel at either ends (Figure 1 ). RE was then collected from the tubes regularly at an interval of 5-7 days for 2 to 3 months and the tubes were filled immediately with fresh distilled water. 
Phenol glycoside from root exudates of $P$. pellucida

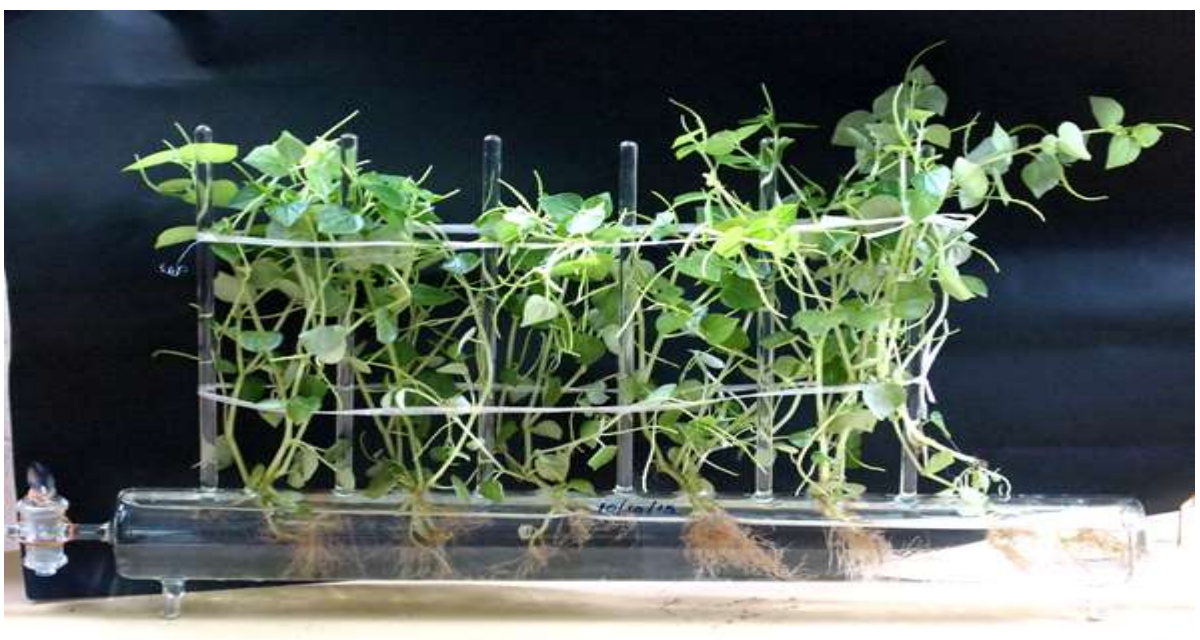

Figure1. Collection of root exudates of P. pellucida L. HBK

\section{Isolation and characterization of active compounds from the root exudates}

The collected REs of $P$. pellucida were evaporated under reduced pressure at $50^{\circ} \mathrm{C}$ by Rotary Vacuum Evaporator (EYELA, Model No. N1-NW) and then extracted with solvents of different polarities - firstly in hexane then ethyl acetate, acetone and methanol. Finally, the compounds were purified by column chromatography and thin layer chromatography (TLC). Compounds were recovered mainly from methanol and water fractions. However, bioactive allelochemicals were recovered from the methanol fraction; so, we placed emphasis on the methanol fraction of $P$. pellucida (hence forth referred to as MFPP).

\section{Column Chromatography}

Columns $(38 \times 4 \mathrm{~cm})$ were tightly packed with silica gel with three different mesh sizes (60-120,100-200, and $230-400$ mesh) up to $25 \mathrm{~cm}$. Silica gel was poured over it. Each column was then run with different solvent systems starting with the non-polar system consisting of ethyl acetate: hexane $(3: 2 \mathrm{v} / \mathrm{v})$ followed by the polar solvent system of acetone: methanol $(9.5: 0.5 ; \mathrm{v} / \mathrm{v})$. Fractions collected every 10 minutes were subjected to TLC analysis.

\section{Thin Layer Chromatography}

Plates $(20 \times 14 \mathrm{~cm})$ were coated uniformly with $0.5 \mathrm{~mm}$ thick layer of Silica gel G and added with $20 \mu \mathrm{l}$ of the fraction (500ppm) by $25 \mu \mathrm{l}$ micropipette and developed up to $18 \mathrm{~cm}$ in glass chamber pre-saturated with mobile phase Ethyl acetate : Hexane (60:40, v/v). Finally, the compound was detected by exposing the loaded plates under UV light and under iodine vapor. Our compounds of interest are highly methanol soluble and was confirmed by $\mathrm{Rf}$ value in the aforementioned solvent system. 
Biswas et al

MS Analysis

MS analysis was done at Indian Institute of Chemical Biology (IICB), Jadavpur, Kolkata 700032. MFPP was then subjected to MS analysis for detecting the exact molecular weight of the compound. Mass Spectra (ESI) was recorded on a Micro mass Q-TOF Micro ${ }^{\mathrm{TM}}$ Spectrometer using positive ion mode.

\section{IR Analysis}

IR analysis was conducted to confirm the important functional group in the extracted and purified Methanol Fraction of P. pellucida (MFPP) with the help of IR Spectrometer (JASCO-SP-Model No. 410 Spectrometer using sample at $\mathrm{KBr}$ plate available at Indian Institute of Chemical Biology, Jadavpur Kolkata 700032).

'HNMR Analysis

'HNMR (300 MHz, $\left.\mathrm{CDCl}_{3}\right)$ available at Indian Institute of Chemical Biology, Jadavpur, Kolkata 700032, was used for analysis of purified MFPP. For 'H, Pulse Programme is $\mathrm{Zg}$ and number of scan is 64 . 'HNMR spectra were observed on ppm $(0-10)$ scale with end sweep at $0 \mathrm{ppm}$. Samples were analyzed at ambient temperature. $\mathrm{CDCl}_{3}$ was used as solvent for MFPP.

${ }^{13}$ CNMR Analysis

${ }^{13} \mathrm{CNMR}\left(150 \mathrm{MHz}, \mathrm{CDCl}_{3}\right)$ available at Indian Institute of Chemical Biology, Jadavpur, Kolkata 700032, was used for analysis of purified MFPP on ppm (0-200) scale with end sweep at $0 \mathrm{ppm}$. In both cases samples were analyzed at ambient temperature and $\mathrm{CDCl}_{3}$ was used as solvent for dissolving the compound.

Effects of different concentrations of MFPP or methanol fraction of P. pellucida on the germination and subsequent growth of rice, wheat and mustard.

The allelopathic potentials of isolated and purified methanol fraction of $P$. pellucida on the germination and seedling growth of rice, wheat and mustard were determined by bioassay experiments. A stock solution of $1000 \mathrm{ppm}$ of MFPP (40 $\mathrm{mg}$ in $40 \mathrm{~mL}$ distilled water) was prepared from which dilute solutions of 500,250 , $125,62.5,31.25,15.62$ and $8.71 \mathrm{ppm}$ were made. In one experiment, nine sets of petri dish bioassay including control were performed. Each experiment was replicated three times. For the control, $20 \mathrm{ml}$ of distilled water was added instead of the test solution. Seeds were surface-sterilized with $0.1 \%$ mercuric chloride solution, washed with distilled water and placed in petri dishes lined with filter paper. After four days, shoot length and root length in the control and treated sets were measured (Mandal 2001). 
Phenol glycoside from root exudates of Peperomia pellucida

\section{RESULTS}

Isolation and Characterization of Active Allelochemical

TLCAnalysis

After purification MFPP was run on TLC in the solvent system Methanol:Acetone: 5:95. A single yellow spot with $R_{f}$ value 0.68 (Figure 2 ) was revealed in iodine vapour. Purified MFPP is faint yellowish in color and oily at room temperature.

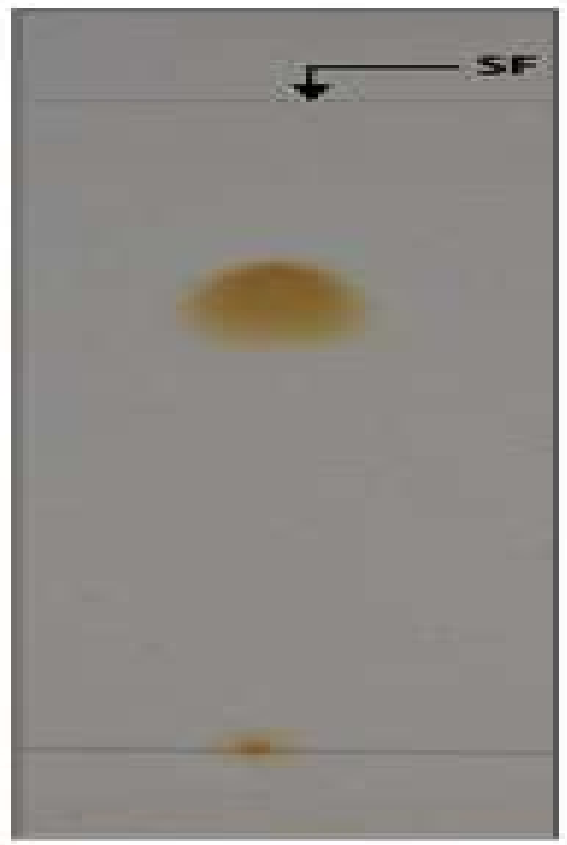

Figure 2. Thin layer chromatogram of purified MFPP or methanol fraction of $P$. pellucida $\mathrm{L}$. HBK. Solvent System -Methanol:Acetone:5:95. Spots visualised under iodine vapour.

\section{MS Analysis}

Mass Spectra of MFPP showed base peak at m/z 281.22 and another small peak at 259.09 corresponding to $[\mathrm{M}+\mathrm{Na}]^{+}$and $[\mathrm{M}+\mathrm{H}]^{+}$respectively. It was also indicated that the molecular weight of the compound is 258 (Figure 3 ).

\section{IR Analysis}

The infrared spectra (Figure 4) of purified MFPP compound showed characteristic stretching bands for $\mathrm{O}-\mathrm{H}, \mathrm{C}=\mathrm{O}$ and $\mathrm{C}=\mathrm{C}$ at 3451,1635 and 553 $\mathrm{cm}^{-1}$ respectively (Silverstein \& Webster 1997). 
Biswas et al

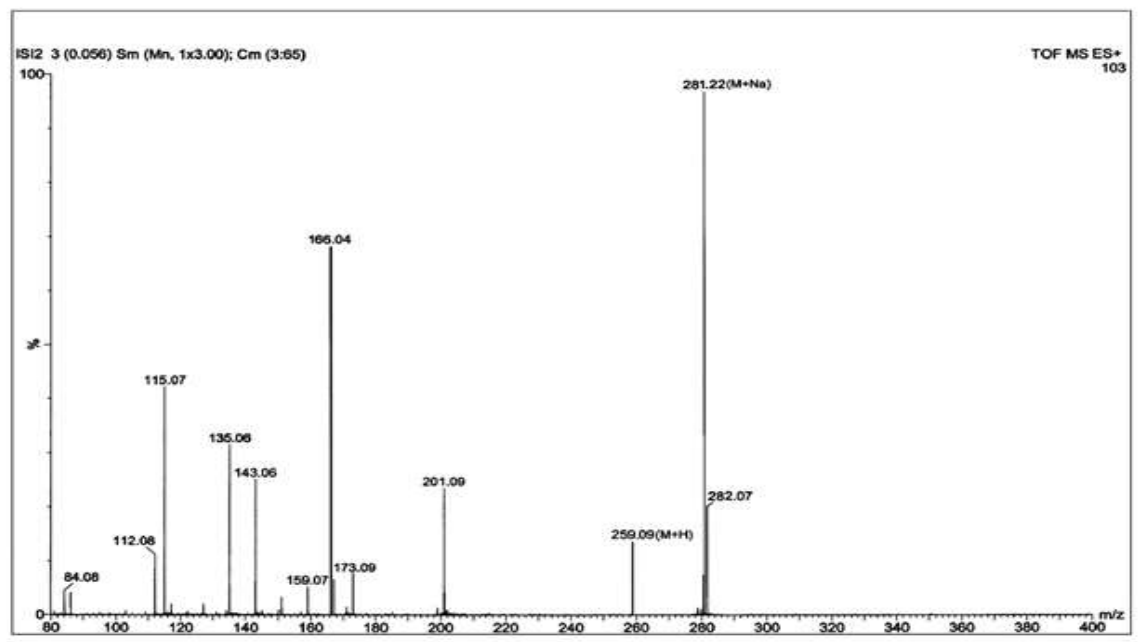

Figure 3. Mass spectra of purified MFPP or methanol fraction of Peperomia pellucida L. HBK

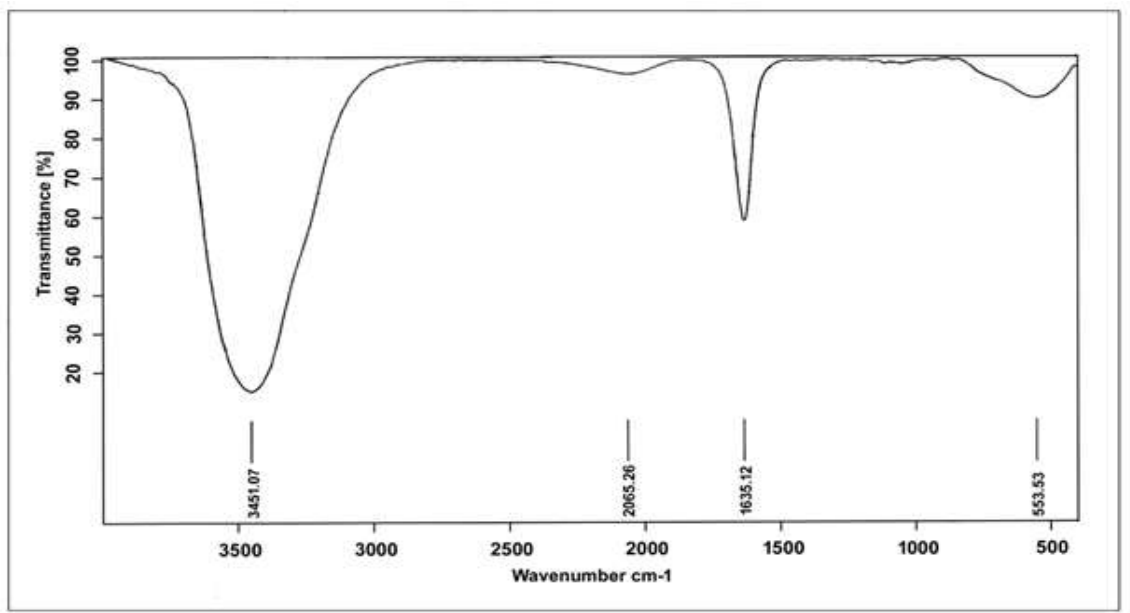

Figure 4. IR Spectra of Purified MFPP of Methanol Fraction of Peperomia pellucida L. HBK

${ }^{7}$ HNMR Analysis

The 'HNMR Spectra indicated peak at 2.27, 2.24 and 2.22 are due to the $\mathrm{OH}$ group of the glycosides moieties. Peak at 5.01 suggested the presence of $\mathrm{OH}$ in the aromatic ring. Peak at $6.66,6.64,6.58$ and 6.56 specified the $\mathrm{CH}$ of the benzene ring. Peak at 5.88, 5.41, 3.91, 3.51 and 3.49 indicated $\mathrm{CH}$ of the glycosides molecule (Figure 5).

\section{${ }^{13}$ CNMR Spectra}

The ${ }^{13}$ CNMR Spectra (Figure 6) showed peak at 138.46, 131.29, 129.24, 124.70 and 121.41 indicating the $\mathrm{CH}$ of the benzene ring. Peak at 144.99 is due to the $-\mathrm{C}-$ of the benzene ring. Peak at $77.68,77.43$ and 77.17 are due to the $\mathrm{CDCl}_{3}$ solvent 
Phenol glycoside from root exudates of Peperomia pellucida

Peak at 98.76, 92.10, 75.32, 72.95 and 67.41 indicated $\mathrm{CH}$ of the glycosides molecule. No peak appeared after 50 suggested the absence of aliphatic chain.

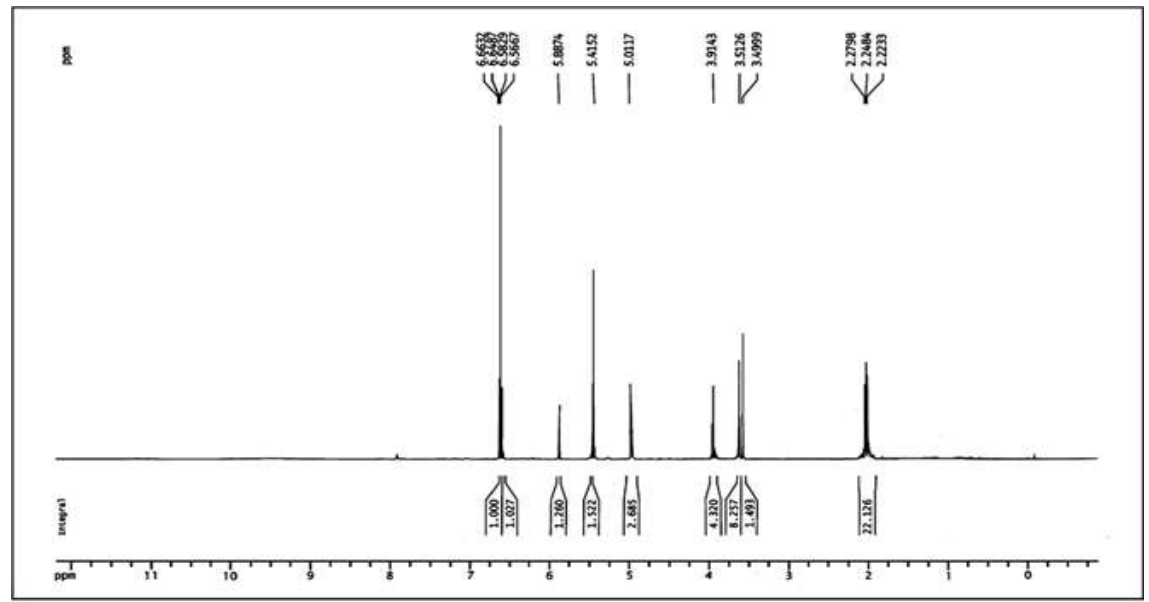

Figure 5. 'HNMR spectra of purified MFPP or methanol fraction of Peperomia pellucida L. HBK

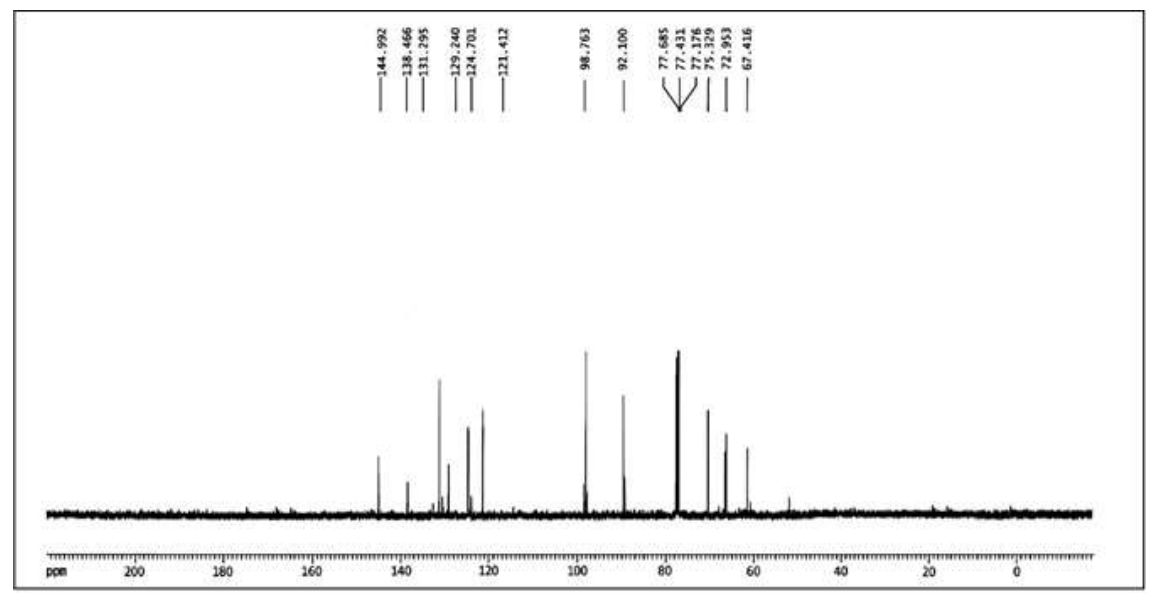

Figure $6 .{ }^{13}$ CNMR spectra of purified MFPP or methanol fraction of Peperomia pellucida L. HBK

Spectral analyses viz IR, MS and NMR suggested the compound to be 6-(4hydroxyphenoxy)-tetrahydro-2H-pyran-2, 3, 4, 5-tetraol with mol. wt. 258 or shortly phenol glycoside (Figure 7).

Effects of MFPP or methanol fraction of P. pellucida different concentrations on the germination and subsequent growth of rice, wheat and mustard

MFPP showed maximum inhibitory activity on rice than in wheat and mustard seed germination. In rice, it showed strong inhibitory activity (78 to 100\%) on both shoot and root length from 1000ppm to $250 \mathrm{ppm}$ concentration while in the case of 
wheat, MFPP exhibited $64.58 \%$ inhibition in shoot length and $68.76 \%$ inhibition in root length. In case of mustard seeds, MFPP showed concentration-dependent inhibition and stimulation of both shoot and root length. At a concentration of 62.5, 31.25 and $7.81 \mathrm{ppm}$, MFPP revealed stimulatory activity on both shoot and root length (Figure 8).

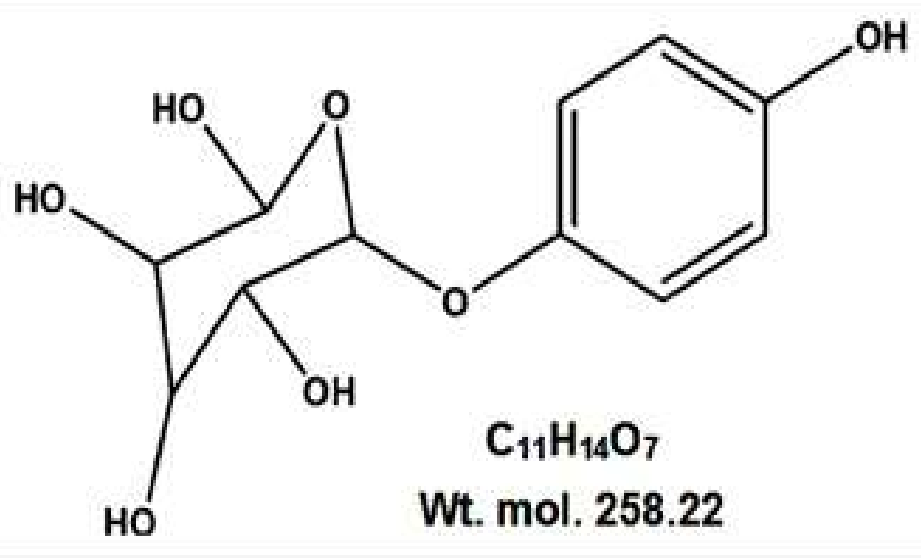

Figure7. Molecular structure of purified MFPP or methanol fraction of $P$. pellucida L. HBK

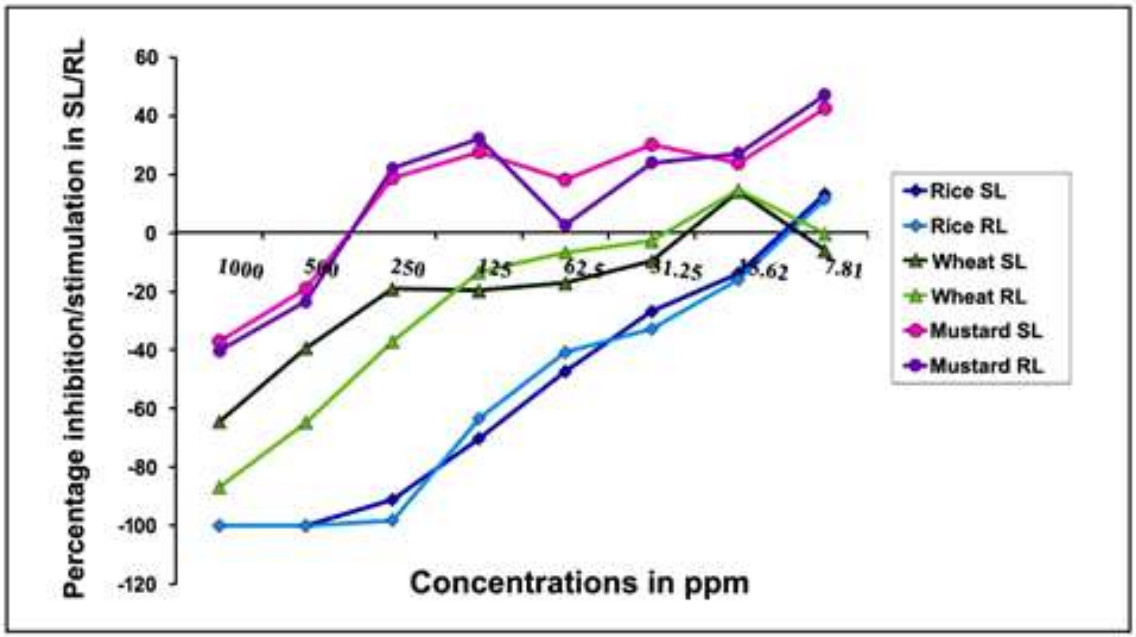

Figure 8. Effects of purified MFPP or methanol fraction of $P$. pellucida at different concentrations on both shoot length (SL) and root length growth of rice, mustard and gram. Correlation is significant at 0.01 level (2-tailed) 
Phenol glycoside from root exudates of Peperomia pellucida

\section{DISCUSSION}

Peperomia pellucida has a long and rich history of medicinal applications across American and Asian countries. Ethno-botanical studies of the plant reveal that the whole plant has been in medicinal use for a long time. Antioxidant properties of $P$. pellucida have also been well documented (Oloyede et al 2011, Mutee et al 2009, Pawlack et al 2010). A qualitative phytochemical analysis of the aqueous extract of $P$. pellucida showed that it contained alkanoids, tannins, saponins, and flavonoids (Ojo et al 2012). Khan et al (2010) isolated xanthone glycoside, specifically patuloside A (3- $\beta$-D-glucopyranosyloxy-1,5,6-trihydroxy$9 \mathrm{H}$-xanthene-9-one), from leaves of $P$. pellucida. The essential oil from the whole plant showed fungicidal activity at a minimum inhibitory concentration of 2,000 ppm with a wide range of toxicity and quick killing activity (Moreira et al 1999, da Silva et al 1999 \& De Lira et al 2009). Singh et al (1983) also reported that the oil of $P$. pellucida was active up to $80^{\circ} \mathrm{C}$.

In Bolivia, a decoction of root of Peperomia has been used for the treatment of fevers. The extract of the aerial part of the plant has been reported to be applied to cure wounds. Mufioz et al (2000) have studied natural bioactive compounds in the extract of Peperomia in Bolivia through multidisciplinary approach. Bayma (2000) identified a dirmeric ArC2 compound from P. pellucida.

In our present study, a new phenol glycocide or [(6-(4-hydroxyphenoxy)tetrahydro-2H-pyran-2,3,4,5-tetraol); $\mathrm{C}_{11} \mathrm{H}_{14} \mathrm{O}_{7} ; \mathrm{Mol}$. Wt. 258] has been isolated and purified from the root exudates of $P$. pellucida, whereas a xanthone glycoside, specifically patuloside A (3- $\beta$-D-glucopyranosyloxy-1,5,6-trihydroxy- $9 \mathrm{H}$ xanthene-9-one) was isolated from leaves of $P$. pellucida (Khan et al 2010). This compound also showed concentration-dependent inhibitory activity on rice, wheat and gram seeds. This inhibitory activity was higher on rice than in wheat. In case of mustard, it revealed stimulatory activity after $500 \mathrm{ppm}$. Therefore, this new phenol glycoside probably acts as allelopathic agents in P. pellucida. The secretion of phenol glycoside may provide a competitive advantage for this plant and promotes its invasion.

Phenol glycosides are commonly found as plant metabolites, but little is known about their functional significance. Reichardt et al (1988) found several phenol glycosides in two woody species, namely, Populus balsamifera and $P$. tremuloides in which they contribute to plant defense by converting to active defensive chemicals in damaged plant tissues. From the dried leaves of Eucalyptus cypellocarpa, three new phenol glycosides acylated with (+)oleuropeic acid, cypellocarpins A (1), B (2), and C have been isolated. These compounds also suppressed an in vivo two-stage carcinogenesis induced with nitric oxide and TPA on mouse skin (Ito et al 2000). Agarwal et al (1995) isolated two new glycosides, the triterpenoid glycoside 19a-hydroxyurs-12-ene-24, 28dioate 3-0- $\beta$ - $d$-xylopyranoside and the phenol glycoside 2-isoprenyl-5-

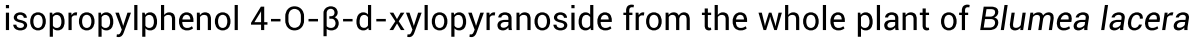
and their structures elucidated by means of spectral and chemical studies. From the roots of Picrorhiza kurrooa, a new iridoid glycoside, 6-feruloylcatalpol has been isolated along with veronicoside and minecoside and two phenol glucosides, picein and rosin (Stuppner \& Wagner 1989). Middleton and Teramura (1993) observed that flavonol glycosides and carotenoids play a role in protecting soybean from ultraviolet damage. 
Plants containing phenol glycosides considered as potential precursors of defensive metabolites could lead to a new understanding of their roles in crop resistance to pests. These biologically active natural compounds are good prospects for the future chemical preparation of compounds useful as antioxidant, anticancer, antimicrobial, and antibacterial agents.

\section{CONCLUSIONS}

A new phenol glycoside has been isolated from the root exudates of $P$. pellucida which may act as an allelopathic agent and may be responsible for its invasive nature.

\section{ACKNOWLEDGMENT}

We are privileged to convey our sincere gratitude to our respected Director, Prof. Sanghamitra Bandhopadhyay, Indian Statistical Institute, for providing Laboratory facilities and financial support. We are indebted to Prof. Pabitra Banik, Prof-in-Charge, Biological Sciences Division and Dr. Sabyasachi Bhattacharya, Head, Agricultural and Ecological Research Unit, Indian Statistical Institute, for their affectionate encouragement, valuable advice and enormous laboratory facilities.

\section{REFERENCES}

Agarwal R, Singh R, Siddiqui IR \& Singh J. 1995. Triterpenoid and prenylated phenol glycosides from Blumea lacera. Phytochemistry, 38:935-938.

Antoniolli A, Arrigoni-blank M, Dmitrieva E, Franzotti E, Andrade M \& Marchioro M. 2003. Anti-inflammatory and analgesic activity of Peperomia pellucida (L.) HBK (Piperaceae). Journal of Ethnopharmacology, 91:215-218.

Arrigoni-blank MF, Oliveira RL, Mendes SS, Silva PA, Antoniolli ÂR, Vilar JC, Cavalcanti SC \& Blank AF. 2002. Seed germination, phenology, and antiedematogenic activity of Peperomia pellucida (L.) HBK. BMC Pharmacology, 2:12-19.

Bayma JDC, Arruda MSP, Müller AH, Arruda AC \& Canto WC. 2000. A dimeric ArC2 compound from Peperomia pellucida. Phytochemistry, 55:779-782.

Bojo AC, Garcia EA \& Pocsidio GN. 1994. Antibacterial activity of Peperomia pellucida (L.) HBK (Piperaceae). Asia Life Sciences (Philippines), 3:35-44.

da Silva MHL, Zoghbi MDGB, Andrade \& Maia JGS. 1999. The essential oils of Peperomia pellucida Kunth and P. circinnata Link var. circinnata. Flavour and Fragrance Journal, 14:312-314.

De Lira PN, Da Silva JK, Andrade EH, Sousa PJ, Silva NN \& Maia JG. 2009. Essential oil composition of three Peperomia species from the Amazon, Brazil. Natural Product Communications, 4:427-430.

Egwuche RU, Odetola AA \& Erukainure OL. 2011. Preliminary investigation into the chemical properties of Peperomia pellucida L. Research Journal of Photochemistry, 5:48-53. 
Phenol glycoside from root exudates of Peperomia pellucida

ENS EJ, Bremner JB, French K \& Korth J. 2009. Identification of volatile compounds released by roots of an invasive plant, bitou bush (Chrysanthemoides monilifera spp. rotundata), and their inhibition of native seedling growth. Biological Invasions, 11:275-287.

Ghani A. 1998. Medicinal Plants of Bangladesh (p112). Asiatic Society of Bangladesh.

Iqbal S \& Bhanger MI. 2006. Effect of season and production location on antioxidant activity of Moringa oleifera leaves grown in Pakistan. Journal of Food Composition and Analysis, 19: 544-551.

Ito H, Koreishi M, Tokuda H, Nishino H \& Yoshida T. 2000. Cypellocarpins AC, phenol glycosides esterified with oleuropeic acid, from Eucalyptus cypellocarpa. Journal of Natural Products, 63: 253-1257.

Khan A, Rahman M \& Islam MS. 2010. Isolation and bioactivity of a xanthone glycoside from Peperomia pellucida. Life Sciences and Medicine Research, 1: $1-10$.

Khan MR \& Omoloso AD. 2002. Antibacterial activity of Hygrophila stricta and Peperomia pellucida. Fitoterapia, 73: 251-254.

Khosla SN, Singh K \& Sobti SN. 1980. Parthenin from Parthenium hysterophorus is phytotoxic too. Indian Journal of Forestry, 3:261-265.

Mandal S. 2001. Allelopathic activity of root exudates from Leonurus sibiricus $L$. (Raktodrone). Weed Biology and Management, 1: 170-175.

Middleton EM \& Teramura AH. 1993. The role of flavonol glycosides and carotenoids in protecting soybean from Ultraviolet-B damage. Plant Physiology, 103:741-752.

Moreira DL, De Souza PO, Kaplan MAC \& Guimarães EF. 1997. Essential oil analysis of four Peperomia species (Piperaceae). In II WOCMAP Congress Medicinal and Aromatic Plants, Part 1: Biological Resources, Sustainable Use. Conservation and Ethnobotany, 500: 65-70.

Mosango DM. 2008. Peperomia pellucida (L.) Kunth. In Schmelzer GH, GuribFakim A (eds), Prota: Medicinal Plants, 11(1):1. PROTA: Wageningen, The Netherlands.

Muñoz V, Sauvain M, Bourdy G, Arrázola S, Callapa J, Ruiz G, Choque J \& Deharo E. 2000. A search for natural bioactive compounds in Bolivia through a multidisciplinary approach Part III: Evaluation of antimalarial activity of plants used by Alteños Indians. Journal of Ethnopharmacology, 71:123-131.

Mutee AF, Salhimi SM, Yam MF, Lim CP, Abdullah GZ, Ameer OZ, Abdulkarim MF \& Asmawi MZ. 2010. In vivo Anti-inflammatory and in vitro Antioxidant Activities of Peperomia pellucida. International Journal of Pharmacology, 6:686-690.

Ojo 00, Ajayi SS \& Owolabi LO. 2012. Phytochemical screening, anti-nutrient composition, proximate analyses and the antimicrobial activities of the aqueous and organic extracts of bark of Rauvolfia vomitoria and leaves of Peperomia pellucida. International Research Journal of Biochemistry and Bioinformatics, 2:127-134.

Oloyede GK, Onocha PA \& Olaniran BB. 2011. Phytochemical, toxicity, antimicrobial and antioxidant screening of leaf extracts of Peperomia pellucida from Nigeria. Advances in Environmental Biology, 5:3700-3709.

Pawlak K, Bylka W, Jazurek B, Matlawska I, Sikorska M, Manikowski H \& Bialekbylka G. 2010. Antioxidant activity of flavonoids of different polarity, assayed by modified ABTS cation radical decolorization and EPR technique. Acta Biologica Cracoviensia Series Botanica, 52:97-104. 
Ragasa CY, Dumato M \& Rideout JA. 1998. Antifungal compounds from Peperomia pellucida. ACGC Chemical Research Communications, 7:54-61.

Reichardt PB, Clausen TP \& Bryant JP. 1988. Phenol glycosides in plant defense against herbivores (Chapter 10, pp130-142). ACS Symposium Series, American Chemical Society.

Silverstein RM \& Webster FX. 1997. Spectrometric identification of organic compound (6th edn). John Wiley \& Sons, New York.

Singh AK, Dikshit A \& Dixit SN. 1983. Antifungal studies of Peperomia pellucida. Beitrage zur Biologie der Pflanzen, 58:357-368.

Sio SO, Maramb NPC \& Sia IC. 2001. Acute oral toxicity of the freeze dried aqueous extract of peperomia pellucida (L) HBK (ulasimang bato) in mice. Acta Medica Philippina, 37:1-11.

Stuppner H \& Wagner H. 1989. Minor iridoid and phenol glycosides of Picrorhiza kurrooa. Planta Medica, 55:467-469.

Xu S, Li N, Ning MM, Zhou CH, Yang QR \& Wang MW. 2006. Bioactive Compounds from Peperomia pellucida. Journal of Natural Products, 69:247-250. 